\title{
DIALOGUE
}

\section{Science is the search for generalizable processes- clinicians solve complex problems: A reply to Wilson on the importance of not confusing these two things}

\author{
IAN H. ROBERTSON \\ University of Dublin Trinity College, Dublin, Ireland \\ (Received December 22, 2004; Revised March 17, 2005; Accepted March 17, 2005)
}

\section{INTRODUCTION}

Barbara Wilson is a creative and influential clinicianscientist who has dedicated her working life to finding ways to rehabilitate brain-damaged people in all the confusing complexity of their damaged brains and lives. Her behavioral training at the Institute of Psychiatry in London inspired her to apply the powerful methods of applied behavior analysis to shape functionally relevant behaviors in the real-life contexts in which these people have to learn new ways of living. I, on the other hand, have chosen to work with people who have specific cognitive deficits such as unilateral neglect (Robertson et al., 1998), impaired sustained attention (Robertson et al., 1997) or goal-neglect-type executive deficits (e.g., Manly et al., 2002). I have specifically avoided trying to carry out research on people with complex problems, specifically because I tried to understand how these strange interchanges we call rehabilitation actually work (Robertson, 2002; Robertson \& Murre, 1999). In my research (not, I hasten to add, in my clinical practice), I try to identify relatively pure processes that can be replicated anywhere in the world - not to solve the pressing problems of a particular, unique and complex life.

I began to do research on rehabilitation because as a novice clinical neuropsychologist, I witnessed enormous amounts of time and resources being spent on various therapies. A complete newcomer to the field, I asked physicians and therapists to explain what they were doing and how it worked. To my surprise, they could not answer. I read some standard textbooks on rehabilitation and was even more astonished to find out that not only did no coherent basis for

Reprint requests to: Ian H. Robertson, Professor of Psychology, Department of Psychology, Trinity College Dublin, Dublin 2, Ireland. E-mail: Ian.Robertson@tcd.ie how all this activity was supposed to change behavior appear in them-no one seemed be aware of this gap.

Furthermore, I saw strongly expressed views about how therapy should be done-for example always moving the hemiplegic arm with the aid of the unaffected arm - which my research subsequently found might actually be detrimental to the recovery of unilateral neglect (Robertson \& North, 1994). I then developed the counter-intuitive method Limb Activation Training mentioned in Wilson's article (Robertson et al., 1992) that was subsequently shownamong other things - to lead to more than a 1 month reduction in length of hospital stay in acute stroke patients when applied as a non-time-consuming adjunct to standard therapy (Kalra et al., 1997).

This treatment arose out of entirely theoretically driven experimental neuropsychology research (Robertson \& North, 1992; Robertson et al., 2002); had I set out to treat patients with complex disorders while taking into account all the multifarious factors influencing their behaviors, I would never have developed this effective treatment. I may well have had better effects on 1 patient by deploying all my clinical wisdom to treating a range of disorders, but I would never have known how or why they got better and been able to tell others how to apply that to a range of patients. Complex treatment of complex disorders can never be replicated precisely because they are so complex.

There is a puzzling contradiction in Barbara Wilson's piece. Take these two sentences from the same abstract: (1) "Thus claims that cognitive rehabilitation can be rendered effective by following findings from research in the basic cognitive neurosciences cannot be justified"; (2) "Obviously, we can call upon research from the neurosciences to help reduce specific difficulties." I can't really reconcile these two statements, and they demonstrate that Wilson is mistakenly contrasting two non-contrastable processes- 
science versus clinical application of science. Of course you can carry out clinical trials of problem-oriented treatments, as Wilson has done so excellently in her trial of using pager technology in the treatment of a range of different people with memory and executive problems (Wilson et al., 2001). But neither scientist nor clinician should be content to see a clinical benefit without wishing to see others try to understand the processes by which that benefit occurred. Without such a drive to understand, treatments cannot be refined and improved, and tailored in more sophisticated ways to more targeted groups of patients. This would be the equivalent of demonstrating that digitalis can help some types of heart condition, and being content to investigate no further, in spite of the fact that some heart conditions require different types of therapy, and others might be harmed by it.

If I succumb to a heart condition, I wish to be treated by the best and most experienced clinician who can treat me in all my genetic, physiological, psychological and social uniqueness/complexity. This clinician will most certainly not mechanically apply a single treatment-he/she will make judgments about the best combinations of treatment tailored to my circumstances. But I do want there to have been a host of other scientists and clinician scientists building the science base for the various individual therapies that my treating clinician will intelligently deploy. I want them to have understood precisely how these treatments work in a range of semi-artificial situations with highly selected groups of patients before they are made available to my own doctor treating my own unique and complex medical problems.

Rehabilitation has not achieved the recognition and respect that other clinical interventions have, precisely because there have been so little 'back-room' science trying to tie down the processes underpinning rehabilitation. With an entirely admirable impatience to treat pressing problems, rehabilitationists-myself included-(Robertson et al., 1990) have tended to rush into premature clinical trials of essentially ad-hoc treatments. Even where such treatments showed positive results (e.g., Gray et al., 1992), they tend not to be taken up or replicated and end up sitting on the shelf of unexplained clinical outcomes. Without replication, clinical trials are essentially worthless-and ad-hoc trials devoid of a theoretical rationale are hardly ever replicated.

Wilson's statement "Thus claims cognitive rehabilitation can be rendered effective by following findings from research in the basic cognitive neurosciences cannot be justified" is not only contradicted in her own abstract, but in her own research: Wilson's excellent work on errorless learningbased methods of rehabilitation were derived entirely from basic behavioral neuroscience research (Wilson et al., 1994). Her group also successfully applied a theoretically derived procedure for executive disorder that my group had developed to the specific real-life problems of a single patient (Levine et al., 2000). Wilson has also carried out basic cognitive neuroscience research herself, in addition to tackling the complex problems of rehabilitation (Wilson, 1988).
All this makes it hard for me to understand the argument being made in her paper: I think that what she may be wishing to argue is not that cognitive neuroscience cannot improve cognitive rehabilitation-this is plainly wrongbut rather that rehabilitation must concentrate on function in real-life settings. If this is the argument, then I could not agree more. Showing an improvement on a cancellation test is of no use to a patient with unilateral neglect unless that improvement is reflected in improved function in the home. But unless one first shows that the procedure can improve cancellation performance and how it may be doing so, it is premature to move to the complexity of the patient's home. Only once one has some scientific basis for the treatment proposed should one intrude into the complexities of the patient's daily life: I don't want a cardiologist coming near the complexities of my heart condition unless there is a very good scientific basis for the use of the various drugs he/she has at her disposal.

Wilson has long been an advocate of rehabilitating in context. As a behavior analyst, she knows that behaviors do not occur in a vacuum but within social and physical contexts. The question of how such contexts influence cognitive function could be a very fruitful domain of cognitive neuroscience research: that research - it probably is already going on-would doubtless improve our understanding of how to maximize rehabilitation by better applying our knowledge about these general processes. To argue that such a domain of cognitive neuroscience could not make more effective functionally oriented rehabilitation is both strangely nihilistic and counter to the prevailing evidence.

That evidence is formidable. Without the application of cognitive neuroscience to cognitive rehabilitation, the following examples (from a much more extensive array) of effective treatments would never have emerged:

- Acoustically modified speech training for specific language impairment (Tallal et al., 1996)

- Hemianopic dyslexia training (Kerkhoff, 1999)

- Kinaesthetic training for pure alexia (Seki, Yajima et al., 1995)

- Attention and memory retraining in normal ageing (Ball et al., 2002; Stigsdotter-Neely \& Bäckman, 1993)

- Computerized alertness training (Sturm et al., 2004)

- Trunk-control retraining for postural disturbance in hemiplegia (Seze et al., 2001)

- Imagery-based memory training (Kaschel et al., 2002)

- Constraint Induced Movement Therapy for hemiparesis (Miltner et al., 1999; Taub \& Wolf, 1997)

- Vibrotactile neck stimulation for unilateral neglect (Schindler et al., 2002)

- Computerized training of sentence comprehension deficits (Crerar et al., 1996) 
- Prism adaptation training for unilateral neglect (Frassinetti et al., 2002; Rossetti et al., 1998; Schindler et al., 2002)

- Limb Activation Training for unilateral neglect (Robertson et al., 1992; Samuel et al., 2000; Robertson et al., 2002)

- Goal Management Training for executive disorders (Levine et al., 2000)

- Sustained Attention Training for sustained attention deficits (Robertson et al., 1995).

While only some of these methods have been proven using the gold standard of single blind randomized controlled trials, there are many more such trials showing significant effects than is the case for purely clinically derived treatment regimes. Furthermore, no pharmaceutical agent would be allowed into the clinic on the basis of a single trial-it takes at least a decade and a huge number of studies costing enormous amounts of money before a drug is approved for a specific treatment. If we wish rehabilitation to be taken seriously by the medical world, and in particular by funders, then comparable levels of effort must be expended on properly developing and evaluating new methods.

This does not mean that we must succumb to medical models of treatment for rehabilitation, and in the process ignore the whole person, the environment, emotional factors and the general context. As scientists, we must study how these factors intersect with recovery from brain damage, and use the understanding of such mechanisms to enhance our treatments: that is what cognitive neuroscience is all about. Nor does it mean that we should necessarily treat in the social vacuum of the clinic rather than in the reality of the workplace or home.

The example of cognitive therapy for depression stands as an excellent behavioral intervention that has achieved near universal recognition as a treatment of choice for certain categories of depression. It has only achieved this recognition, as a result of two decades of intensive, theoretically derived experimental research followed by a number of rigorous clinical trials. Depression occurs in exactly the same range of individual and social complexity as does brain damage, but that has not prevented cognitive psychologyand more recently cognitive neuroscience-from making a huge contribution to the development of this therapy. Had the advocates of cognitive therapy adopted an anti-theoretical focus on treating depression only in the unique complexity of the individual case and denied the need to understand the processes by which the therapy might work, many tens of thousands of depressed people in the world would have been denied this effective treatment. Neuropsychological rehabilitation requires a similar internationally co-ordinated and theoretically focused approach. It will take at least 10 years, I estimate, for any one treatment to come to the point where cognitive therapy for depression is now-and many millions of dollars of research funding.
I have no doubt that Wilson's unique and important perspective on rehabilitation should be incorporated in such an endeavor. Of course we must ultimately change peoples lives, and not just their performance on neuropsychological tests. But to persuade the opinion-formers that we really can change their lives, we must engage in the hard scientific graft of identifying the intervening processes-of showing how it is we achieve these effects. We will be required to show changes not only in peoples' lives, but in their performance and in their brains (O'Connor et al., 2004; Sturm et al., 2004): the more we do this using all the methods of mainstream science, the more funding will be provided for our research, and the greater the chance will be that neuropsychological rehabilitation methods can approach the acceptance and respect of cognitive therapy. This will require patience and an acceptance that treatments-whether biological or psychological-must have the strongest possible theoretical foundation. Neuropsychological rehabilitation's theoretical home is cognitive neuroscience and if it abandons that home, its future is bleak.

\section{REFERENCES}

Ball, K., Berch, D.B., Helmers, K.F., Jobe, J.B., Leveck, M.D., Marsiske, M., Morris, J.N., Rebok, G.W., Smith, D.M., Tennstedt, S.L., Unverzagt, F.W., \& Willis, S.L. (2002). Effects of cognitive training interventions with older adults: A randomised controlled trial. Journal of the American Medical Association, 13, 2271-2281.

Crerar, M.A., Ellis, A.W., \& Dean, E.C. (1996). Remediation of sentence processing deficits in aphasia using a computer-based microworld. Brain and Language, 52, 229-275.

Frassinetti, F., Angeli, V., Meneghello, F., Avanzi, S., \& Ladavas, E. (2002). Long-lasting amelioration of visuospatial neglect by prism adaptation. Brain, 125, 608-623.

Gray, J.M., Robertson, I.H., Pentland, B., \& Anderson, S.I. (1992). Microcomputer based cognitive rehabilitation for brain damage: A randomised group controlled trial. Neuropsychological Rehabilitation, 2, 97-116.

Kalra, L., Perez, I., Gupta, S., \& Wittink, M. (1997). The influence of visual neglect on stroke rehabilitation. Stroke, 28, 1386-1391.

Kaschel, R., Sala, S.D., Cantagallo, A., Fahlbock, A., Laaksonen, R., \& Kazen, M. (2002). Imagery mnemonics for the rehabilitation of memory: A randomised group controlled trial. Neuropsychological Rehabilitation, 12, 127-153.

Kerkhoff, G. (1999). Restorative and compensatory therapy approaches in cerebral blindness: A review. Restorative Neurology and Neuroscience, 15, 255-271.

Levine, B., Robertson, I., Clare, L., Carter, G., Hong, J., \& Wilson, B.A. (2000). Rehabilitation of executive functioning: An experimental-clinical validation of Goal Management Training. Journal of the International Neuropsychological Society, 6, 299-312.

Manly, T., Hawkins, K., Evans, J., Woldt, K., \& Robertson, I.H. (2002). Rehabilitation of executive function: Facilitation of effective goal management on complex tasks using periodic auditory alerts. Neuropsychologia, 40, 271-281.

Miltner, W.H., Bauder, H., Sommer, M., Dettmers, C., \& Taub, E. (1999). Effects of constraint-induced movement therapy on 
patients with chronic motor deficits after stroke: A replication. Stroke, 30, 586-592.

O’Connor, C., Manly, T., Robertson, I.H., Hevenor, S.J., \& Levine, B. (2004). An fMRI study of sustained attention with endogenous and exogenous engagement. Brain and Cognition, 54, 133-135.

Robertson, I., Gray, J., Pentland, B., \& Waite, L. (1990). A randomised controlled trial of computerised cognitive rehabilitation for unilateral left neglect. Archives of Physical Medicine and Rehabilitation, 71, 663-668.

Robertson, I.H. (2002). Cognitive neuroscience and brain rehabilitation: A promise kept (Editorial). Journal of Neurology, Neurosurgery and Psychiatry, 73, 357.

Robertson, I.H., Manly, T., Andrade, J., Baddeley, B.T., \& Yiend, J. (1997). Oops!: Performance correlates of everyday attentional failures in traumatic brain injured and normal subjects: The Sustained Attention to Response Task (SART). Neuropsychologia, 35, 747-758.

Robertson, I.H., Mattingley, J.B., Rorden, C., \& Driver, J. (1998). Phasic alerting of neglect patients overcomes their spatial deficit in visual awareness. Nature, 395, 169-172.

Robertson, I.H., McMillan, T.M., MacLeod, E., \& Brock, D. (2002). Rehabilitation by Limb Activation Training (LAT) reduces impairment in unilateral neglect patients: A single-blind randomised control trial. Neuropsychological Rehabilitation, 12, 439-454.

Robertson, I.H. \& Murre, J.M.J. (1999). Rehabilitation of brain damage: Brain plasticity and principles of guided recovery. Psychological Bulletin, 125, 544-575.

Robertson, I.H. \& North, N. (1992). Spatio-motor cueing in unilateral neglect: The role of hemispace, hand and motor activation. Neuropsychologia, 30, 553-563.

Robertson, I.H. \& North, N. (1994). One hand is better than two: Motor extinction of left hand advantage in unilateral neglect. Neuropsychologia, 32, 1-11.

Robertson, I.H., North, N., \& Geggie, C. (1992). Spatio-motor cueing in unilateral neglect: Three single case studies of its therapeutic effectiveness. Journal of Neurology, Neurosurgery and Psychiatry, 55, 799-805.

Robertson, I.H., Tegner, R., Tham, K., Lo, A., Nimmo-Smith, I. (1995). Sustained attention training for unilateral neglect: theoretical and rehabilitation implications. Journal of Clinical and Experimental Neuropsychology, 17, 416-430.

Rossetti, Y., Rode, G., Pisella, L., Farne, A., Li, L., \& Boisson, D. (1998). Prism adaptation to a rightward optical deviation rehabilitates left hemispatial neglect. Nature, 395, 166-169.
Samuel, C., Louis-Dreyfus, A., Kaschel, R., Makiela, E., Troubat, M., \& Aselmi, N. (2000). Rehabilitation of very severe unilateral neglect by visuo-spatial cueing: Two single case studies. Neuropsychological Rehabilitation, 10, 385-399.

Schindler, I., Kerkhoff, G., Karnath, H.-O., Keller, I., \& Goldenberg, G. (2002). Neck muscle vibration induces lasting recovery in unilateral neglect. Journal of Neurology, Neurosurgery and Psychiatry, 73, 412-419.

Seki, K., Yajima, M., \& Sugishita, M. (1995). The efficacy of kinaesthetic reading treatments for pure alexia. Neuropsychologia, 33, 595-609.

Seze, M.D., Wiart, L., \& Bon-Saint-Come, A. (2001). Rehabilitation of postural disturbances of hemiplegic patients by using trunk control retraining during exploratory exercises. Archives of Physical Medicine and Rehabilitation, 82, 793-800.

Stigsdotter-Neely, A. \& Bäckman, L. (1993). Long-term maintenance of gains from memory training in older adults: Two 3 1/2 year follow-up studies. Journal of Gerontology, 48, 233-237.

Sturm, W., Longonia, F., Weisa, S., Specht, K., Herzog, H., \& Vohna, R. (2004). Functional reorganisation in patients with right-hemisphere stroke after training of alertness: A longitudinal PET and fMRI study in eight cases. Neuropsychologia, 42, 434-450.

Tallal, P., Miller, S.L., Bedi, G., Byma, G., Wang, X.Q., \& Nagarajan, S.S. (1996). Language comprehension in languagelearning impaired children improved with acoustically modified speech. Science, 271, 81-84.

Taub, E. \& Wolf, S.L. (1997). Constraint induced movement techniques to facilitate upper extremity use in stroke patients. Topics in Stroke Rehabilitation, 3, 38-61.

Wilson, B.A. (1988). Remediation of apraxia following an anaesthetic accident. In J. West \& P. Spinks (Eds.), Clinical psychology in action (pp. 178-183). London: John Wright \& Sons.

Wilson, B.A., Baddeley, A.D., Evans, J.J., \& Shiel, A. (1994). Errorless learning in the rehabilitation of memory impaired people. Neuropsychological Rehabilitation, 4, 307-326.

Wilson, B.A., Emslie, H.C., Quirk, K., \& Evans, J.J. (2001). Reducing everyday memory and planning problems by means of a paging system: A randomised control crossover study. Journal of Neurology, Neurosurgery and Psychiatry, 70, 477-482.

Wilson, F.A.W., Scalaidhe, S.P.O., \& Goldman-Rakic, P.S. (1993). Dissociation of object and spatial processing domains in primate prefrontal cortex. Science, 260, 1955-1958. 